\title{
Evaluation of the Leishmania Surveillance System, Yemen, 2021
}

\author{
Magdi Aldaeri ${ }^{1}$, MBBS, MSc; Labiba Anam ${ }^{1}$, MSc; Sami Alhaidari ${ }^{2}$, MSc \\ ${ }^{1}$ Yemen Field Epidemiology Training Program, Sana'a, Yemen \\ ${ }^{2}$ Neglected Tropical Diseases Department, Ministry of Public Health and Population, Sana'a, Yemen \\ Corresponding Author: \\ Magdi Aldaeri, MBBS, MSc \\ Yemen Field Epidemiology Training Program \\ Ministry of Public Health and Population \\ Sana'a \\ Yemen \\ Phone: 9670734861432 \\ Email: magdid14@gmail.com
}

\section{Abstract}

Background: Control of preventive chemotherapy-targeted neglected tropical diseases (PC-NTDs) depends on strengthened health systems. Efficient health information systems provide a stimulus to reaching the sustainable development goal aimed at ending PC-NTD epidemics. However, there is limited assessment of surveillance system functions linked to PC-NTDs that are hinged on the optimal performance of surveillance system attributes.

Objective: The aim of this study was to assess the usefulness and performance of the National Leishmania Control Program (NLCP), and to estimate the strength and weakness points of the system.

Methods: We followed the updated six steps of Centers for Diseases Control and Prevention (CDC) guidelines for evaluating public health surveillance systems. Data were collected using in-depth interviews with relevant stakeholders at the central level and semistructured questionnaires at the peripheral level. We used questions (yes, no) to assess the usefulness and a 5-point Likert scale to measure the attributes. The final score was interpreted as poor $(<60)$, average $(60-80)$, and good $(>80)$.

Results: The NLCP seemed to be useful $(86 \%)$ and some of its objectives were met. The system has average performance in flexibility (78\%), simplicity (64\%), acceptability (80\%), and data quality (65\%). Poor performance was indicated for stability $(33 \%)$ and timeliness $(8 \%)$. The overall performance of the NLCP was deemed to be poor (55\%). Continuation of the system was the strongest point, whereas the lack of governmental and agency funds was the weakest point.

Conclusions: The NLCP was found to be useful regarding the attributes assessed; simplicity, flexibility, acceptability, and data quality were deemed to be average, whereas stability and timeliness were considered to be poor. Governmental financial support to the program is highly recommended. In addition, creating a database for staff at the peripheral level and expanding the number of health facilities that serve as Leishmania units are required.

(iproc 2022;8(1):e36595) doi: 10.2196/36595

\section{KEYWORDS}

evaluation; surveillance system; Leishmania; Yemen

Edited by Y Khader; this is a non-peer-reviewed article. Submitted 18.01.22; accepted 19.01.22; published 07.02.22.

Please cite as:

Aldaeri M, Anam L, Alhaidari S

Evaluation of the Leishmania Surveillance System, Yemen, 2021

iproc 2022;8(1):e36595

URL: https://www.iproc.org/2022/1/e36595

doi: $10.2196 / 36595$

PMID: 
(C) Magdi Aldaeri, Labiba Anam, Sami Alhaidari. Originally published in Iproceedings (https://www.iproc.org), 07.02.2022. This is an open-access article distributed under the terms of the Creative Commons Attribution License (https://creativecommons.org/licenses/by/4.0/), which permits unrestricted use, distribution, and reproduction in any medium, provided the original work, first published in Iproceedings, is properly cited. The complete bibliographic information, a link to the original publication on https://www.iproc.org/, as well as this copyright and license information must be included. 